\title{
Relation between Visual Motor Integration and Handwriting in Students of Elementary School
}

\author{
Simone Aparecida Capellini ${ }^{1}$, Catia Giaconi ${ }^{2}$, Giseli Donadon Germano ${ }^{1}$ \\ ${ }^{1}$ Investigation Learning Disabilities Laboratory (LIDA), Speech and Hearing Sciences Department, São Paulo State University \\ "Júlio de Mesquita Filho" UNESP, Marília, Brazil \\ ${ }^{2}$ Department of Education, Cultural Heritage and Tourism, University of Macerata, UNIMC, Macerata, Italy \\ Email: giseliger@yahoo.com.br
}

How to cite this paper: Capellini, S. A., Giaconi, C., \& Germano, G. D. (2017). Relation between Visual Motor Integration and Handwriting in Students of Elementary School. Psychology, 8, 258-270.

http://dx.doi.org/10.4236/psych.2017.82015

Received: November 10, 2016

Accepted: January 20, 2017

Published: January 23, 2017

Copyright $\odot 2017$ by authors and Scientific Research Publishing Inc. This work is licensed under the Creative Commons Attribution International License (CC BY 4.0).

http://creativecommons.org/licenses/by/4.0/

\begin{abstract}
Aim: To characterize, compare the related visual motor integration and handwriting performance of Brazilian students of elementary schools. A total of 50 students from the 1st to 5th grade level of elementary school participated in this study. The students were divided into: Group I (GI): 10 students enrolled in the 1st grade; Group II (GII): 10 students enrolled in the 2nd grade; Group III (GIII): 10 students enrolled in the 3th grade; Group IV (GIV): 10 students enrolled in the 4th grade and Group V (GV): 10 students enrolled in the 5th grade. After the sign of consent form by parents, the students were submitted to the application of visual motor integration test and handwriting assessment. Results: The results showed that there was performance alteration of the GI, GII, GIII, GIV and GV students in visual motor integration, visual perception and motor coordination; showed the presence of dysgraphia in all groups; and found that the students of GI and GV were the students with the greatest impairment in visual motor integration and in the quality of handwriting. Conclusion: These findings prove a direct relation between the visual motor integration and handwriting performance of the students of this study.
\end{abstract}

\section{Keywords}

Learning, Motor Skill, Visual Motor Skill, Handwriting

\section{Introduction}

Visomotor integration is defined as a smooth integration between the visoperceptual and motor skills, which requires the ability to translate the visual perception of motor function, or the ability to coordinate hand and eye, and therefore has an important role in the child's academic development, being crucial for the 
acquisition of reading and writing skills in the first four grades of elementary school (Lahav, Apter, \& Ratzonl, 2013; Pereira, Araújo, \& Braccialli, 2011).

The visomotor integration requires the conjunction of voluntary attention and the act of programming and reprogramming of the body movements that will perform motor activity. Thus, the effectiveness of speed programming occurs in the way that tactile-perceptual information fits into visual information (Germano et al., 2013).

Problems in visomotor integration (for example, copy a figure) could be due to visual perception problems (i.e. to draw a circle) and/or motor skills (i.e. make the lines of a drawing) and the integration of both. Such changes may compromise the learning of academic skills such as writing and mathematics, which is detrimental in the school progress, and as a result there is the appearance of emotion, behavior and learning (Germano et al., 2013; Pieters et al., 2012).

The learning of writing skills depends on visual perception, as it is used to construct internal representations of visual information that provides characteristics such as shape, size, position in space and distance of letters. Motor coordination is responsible to several actions, from sensory grasping to proper sequencing to produce the necessary movements for the expression of written handwriting (Andrade et al., 2012; Fusco et al., 2011; Okuda et al., 2011; Vinter \& Chartrel, 2010).

Handwriting requires finely graded manipulation of pencils to produce letter forms, in a fluent and ballistic manner, with a specific orientation and size, in a specific serial order, and in specific positions on a writing surface (van Galen, 1993). Furthermore, according to Sovik and Arntzen (1991), fluent writing is produced by an integrated pattern of coordinated movements subject to visual monitoring and sensorimotor feed-back (Tseng \& Chow, 2000).

Much can also be inferred from the various ways in which handwriters do not achieve functional competence. Handwriting can be deficient either in terms of legibility or in terms of speed. Common handwriting problems such as incorrect letter formation, poor alignment, reversals, uneven size of letters, irregular spacing between letters and words, and slow motor speed (Alston \& Taylor, 1987; Johnson \& Carlisle, 1996) do not necessarily arise from identical underlying mechanisms. Most studies to date, however, have focused primarily on the relationship between illegibility and various visual-perception skills, fine motor skills and visual-motor integration. Wallen, Duff, Goyen and Froude (2013) indicated that automatic handwriting that is legible, generated at sufficient speed and without need for conscious attention is predicated on effective orthographic-motor integration and not simply on motor processes.

One of the manifestations arising from visomotor perception change is the dysgraphia, which according to the American Psychiatric Association, 2013 is described as a neurodevelopmental disorders, such as a specific learning disorder of written expression and can be a predictor or co-occur with other learning problems. The dysgraphia can be further classified into two types: the 
perceptual and motor dysgraphia. The perceptual dysgraphia is described, as a difficulty of the student cannot make the relationship between the symbolic system and spellings that represent sounds, words and phrases. The motor dysgraphia is described as the students can speak and read, but find difficulties in fine motor skills to write letters, words and numbers; in other words, they are able to see the graphic picture, but they cannot make the moves to write (Martins et al., 2013).

This study based on this hypothesis that the ability of visual-motor integration is directly related to the handwriting performance independent of the grade level. Based on the above, this study aimed to characterize and compare the perceptual performance and visomotor and writing in Brazilian students from the 1 st to 5 th grade of elementary school.

\section{Method}

This study was conducted after approval by the Ethics Committee of the Faculty of Philosophy and Sciences, of University of State of São Paulo "Júlio de Mesquita Filho” UNESP/ Marília-SP, under protocol No 0733/2013.

A total of 50 students participated of this study, from 1st to 5th grade level of Elementary Education, of public schools from Marilia-SP, aged 6:00 years to 11:04 years-old, of both genders, 29 (58\%) males and 21 (42\%) females divided into Group I (GI): composed of 10 students from 1st grade level (5 males: 5 female). Group II (GII): composed of 10 students from 2 nd grade level (5 males: 5 female). Group III (GIII): composed of 10 students from 3rd grade level (6 males:4 female). Group IV (GIV): composed of 10 students from 4th grade level (7 males:3 female). Group V (GV): composed of 10 students from 5 th grade level (6 males:4 female).

In this study, we considered as exclusion criteria students with any sensory, motor or cognitive impairment and the non-submission of Informed Consent and signed by parents or guardians. As inclusion criteria students with Informed Consent signed by parent or guardian, students without of presence of sensory, motor or cognitive impairment, hearing or visual disabilities, that were constant school records. The classification of the socioeconomic level was performed based on the statistical study of the Socioeconomic Development Index (Foundation of Economy and Statistics, 2003), thus guaranteeing the homogeneity of the sample from an average socioeconomic point of view. In addition, it is important to highlight that the schools follow the same methodology of literacy, that is, the schools follow national curricular parameters.

For this research, the following procedures were used:

a) The Beery-Buktenica Developmental Test of Visual-Motor Integration-6th edition (Beery \& Beery, 2010). The test has the aim to assess the extent to which individuals can integrate their visual and motor abilities. This consists in a developmental sequence of geometric forms to be imitated or copied with paper or pencil. It comprises three tests: Visual-Motor Integration (VMI), Visual Perception (VP) and the Motor Coordination (MC). The punctuation is performed as 
"one" for correct answer and "zero" for incorrect. The score is standardized to identify difficulties in visual-motor integration, visual perception and motor coordination. The VMI test is composed by 30 items, including imitated and copy forms. The VP tests are composed by 30 items, including identity of parts of own body and point the match picture. The MC tests are also composed by 30 items, including climb on a chair, hold a pencil with thumb and fingers, hold the paper with one hand as the students draws and also trace the stimulus forms with a pencil without going outside double-lined paths. After, the raw score of each test were converted to a number normalized (standard score), which can be interpreted as relative levels, enable to make the performance classification of the student in very low, low, below average, average, above average, high and very high.

b) Dysgraphia Scale (Lorenzini, 2003): composed of 10 assessment items for writing, (floating lines, ascending/descendant lines; irregular spaces between words; retouched letters; curvature and angle of the $\mathrm{M}, \mathrm{N}, \mathrm{U}, \mathrm{V}$; junction points, collisions and adhesions; sudden movements; dimensions of irregularities and bad ways). The scoring criteria used for performance analysis in the writing of students in this study is proposed by Lorenzini (2003), and the overall score for each written ranged from zero to seventeen points and then considered dysgraphia every students with overall equal or greater than eight and a half points equivalent to $50 \%$ of the total score. This procedure was chosen because this is the only Brazilian scale that measures the readability of handwriting.

In order to make the statistical analysis, the program used was the SPSS (Statistical Package for Social Sciences), version 21.0. A significance level of 5\% (0.05) was adopted for the statistical tests. Non-parametric tests were used, which assumes that the distribution of its experimental data is not normal, that is, not homogeneous.

\section{Results}

Table 1 presents mean, standard deviation, median, and p-value regarding the comparison between the performance of students of GI, GII, GIII, GIV and GV in VMI, VP and MC subtests analyzed with the Kruskal-Wallis test.

In Table 1, it was possible to observe that there were statistical differences between all groups in VMI, VP and MC tests, which demonstrates that GI presented inferior performance VMI, VP e MC tests when related with others groups.

At Table 1, it was found statistically significant differences in all tests. We can observe that there is not a progression of acquisition and development of the subtests, as in visoperception ( $\mathrm{GI}<\mathrm{GII}<\mathrm{GIII}<\mathrm{GV}<\mathrm{GIV})$, motor coordination $(\mathrm{GI}<\mathrm{GII}<\mathrm{GV}<\mathrm{GIII}<\mathrm{GIV})$ and visomotor integration $(\mathrm{GI}<\mathrm{GII}<\mathrm{GV}<\mathrm{GIII}$ $<$ GIV). As there was difference, we used the Mann-Whitney test, adjusted by Bonferroni correction, to identify which groups are different from each other (Table 2).

Table 2 shows significant difference for Visual-Motor Integration test (VMI) 
Table 1. Distribution of mean, standard deviation and p-value of groups GI, GII, GIII, GIV and GV in VMI, VP and MC tests.

\begin{tabular}{|c|c|c|c|c|c|}
\hline Tests & Group & $\mathrm{N}$ & Mean & $\begin{array}{l}\text { Standard } \\
\text { Deviation }\end{array}$ & $p$-value \\
\hline \multirow[t]{6}{*}{ VMI } & GI & 10 & 13.00 & 2.40 & $<0.001^{\star}$ \\
\hline & GII & 10 & 13.50 & 2.12 & \\
\hline & GIII & 10 & 17.10 & 2.85 & \\
\hline & GIV & 10 & 20.50 & 3.75 & \\
\hline & GV & 10 & 16.40 & 3.47 & \\
\hline & Total & 50 & 16.10 & 3.96 & \\
\hline \multirow[t]{6}{*}{ VP } & GI & 10 & 18.70 & 4.27 & $0.007^{\star}$ \\
\hline & GII & 10 & 19.70 & 3.09 & \\
\hline & GIII & 10 & 20.30 & 3.53 & \\
\hline & GIV & 10 & 24.90 & 3.67 & \\
\hline & GV & 10 & 22.40 & 3.10 & \\
\hline & Total & 50 & 21.20 & 4.08 & \\
\hline \multirow[t]{6}{*}{$\mathrm{MC}$} & GI & 10 & 19.20 & 3.19 & $0.002^{*}$ \\
\hline & GII & 10 & 21.60 & 3.69 & \\
\hline & GIII & 10 & 24.30 & 2.00 & \\
\hline & GIV & 10 & 25.90 & 4.25 & \\
\hline & GV & 10 & 23.20 & 4.71 & \\
\hline & Total & 50 & 22.84 & 4.23 & \\
\hline
\end{tabular}

Legend: VMI: visual-motor integration; VP: visual perception; MC: motor coordination.

Table 2. Comparison between performance of groups GI, GII, GIII, GIV and GV in VMI, VP and MC tests.

\begin{tabular}{ccccccccc}
\hline \multicolumn{7}{c}{ Groups } \\
\hline Tests & I vs. II & I vs. III & I vs. IV & I vs. V & II vs. III & II vs. IV & II vs. V & III vs. IV \\
\hline VMI & 0.490 & 0.008 & $<0.001^{*}$ & 0.022 & 0.011 & $<0.001^{*}$ & 0.044 & 0.030 \\
VP & 0.790 & 0.595 & $0.004^{\star}$ & 0.033 & 0.761 & 0.008 & 0.062 & 0.015 \\
MC & 0.095 & $<0.001^{*}$ & $0.002^{\star}$ & 0.040 & 0.061 & 0.015 & 0.363 & 0.067 \\
\hline
\end{tabular}

Legend: VMI: visual-motor integration; VP: visual perception; MC: motor coordination. (Bonferroni alpha $=0.005116)$.

between GI and GIV, and GII and GIV. There was significant difference for Visual Perception (VP) test regarding the comparison between GI and GIV. Also, there was significant difference for Motor Coordination test between groups GI and GII, GI and GIV. There was no statistical difference between GIII and GV, GIV and GV in VMI, VP and MC tests. Table 3 shows the distribution of mean, standard deviation, and $p$-value considering the comparison of visual-motor integration, visual perception and motor coordination in each group of GI, GII, GIII, GIV and GV, analyzed by Friedman test.

The results showed that were significant differences between all tests in all groups, and the groups presented the same performance standard when we observe the mean $(\mathrm{MC}>\mathrm{VI}>\mathrm{VMI})$. Because of these findings, we applied the test of 
Table 3. Comparison between VMI, VP and MC tests by each group performance.

\begin{tabular}{cccccc}
\hline Group & Variable & $\mathrm{n}$ & Mean & Standard deviation & $p$-value \\
\hline GI & VMI & 10 & 13.00 & 2.40 & $0.021^{*}$ \\
& VP & 10 & 18.70 & 4.27 & \\
\multirow{3}{*}{ GII } & MC & 10 & 19.20 & 3.19 & $0.003^{*}$ \\
& VMI & 10 & 13.50 & 2.12 & \\
& VP & 10 & 19.70 & 3.09 & $0.003^{*}$ \\
GIII & MC & 10 & 21.60 & 3.69 & \\
& VMI & 10 & 17.10 & 2.85 & $0.016^{*}$ \\
& VP & 10 & 20.30 & 3.53 & \\
GIV & MC & 10 & 24.30 & 2.00 & \\
& VMI & 10 & 20.50 & 3.75 & $0.001^{*}$ \\
& VP & 10 & 24.90 & 3.67 & \\
& MC & 10 & 25.90 & 4.25 & \\
& VMI & 10 & 16.40 & 3.47 & \\
& VP & 10 & 22.40 & 3.10 & \\
& MC & 10 & 23.20 & 4.71 & \\
\hline
\end{tabular}

Legend: VMI: visual-motor integration; VP: visual perception; MC: motor coordination.

Wilcoxon Signed Posts, adjusted by Bonferroni correction, to see which tests differ from each other (Table 4).

The results of Table 4 indicated that for group GI, GII and GV there was significant differences between the comparison of VP and VMI test (mean VP > mean VMI) and MC and VMI test (mean MC > mean VMI). For the group GIV there was no significant differences between the tests. Regarding the GIII, there was a significant difference between the MC and VMI test (mean MC > mean VMI).

Table 5 shows the frequency and percentage of groups GI, GII, GIII, GIV and GV the regarding the performance classification in VMI, VP and MC tests, analyzed by Likelihood Ratio Test.

In Table 5, the results showed that there was no significant difference between the classification of VMI, VP and MC between the groups. In addition, none of the groups received the classification very high in any tests.

Regarding the VMI test, $80 \%$ of the students of GI had below average performance (VL, L, BA) and only $20 \%$ had performance on average; $90 \%$ of the students of GII had below average performance (VL, L, BA) and only $10 \%$ had performance on average; $60 \%$ of the students of GIII had below average performance (VL, L, BA) and only $40 \%$ had performance on average; $90 \%$ of the students of GIV had below average performance (VL, L, BA) and only $10 \%$ had performance on average; and $100 \%$ of the students of GV had below average performance (VL, L, BA).

Regarding the VP test, $90 \%$ of the students of GI had performance on average or above (A, AA, H) and only $10 \%$ had below average performance $(\mathrm{VL}) ; 60 \%$ of the students of GII had performance on average or above (A, H) and only $40 \%$ had below average performance (BA); $70 \%$ of the students of GIV had 
Table 4. Comparison between the test of VMI, VP and MC in relation with each group performance.

\begin{tabular}{cccccc}
\hline Tests & GI & GII & GIII & GIV & GV \\
\hline VP - VMI & $0.009^{*}$ & $0.011^{\star}$ & 0.092 & 0.092 & $0.008^{\star}$ \\
MC - VMI & $0.012^{*}$ & $0.007^{*}$ & $0.005^{*}$ & 0.074 & $0.007^{\star}$ \\
MC - VP & 0.677 & 0.152 & $0.012^{*}$ & 0.360 & 0.720
\end{tabular}

Legend: VMI: visual-motor integration; VP: visual perception; MC: motor coordination. (Bonferroni alpha $=0.016952$ ).

Table 5. Distribution of frequency and percentage of the classification of VMI, VP and MC tests for GI, GII, GIII, GIV and GV.

\begin{tabular}{|c|c|c|c|c|c|c|c|c|c|c|c|c|}
\hline \multirow[b]{2}{*}{ Tests } & \multirow[b]{2}{*}{$\mathrm{CL}$} & \multicolumn{2}{|c|}{ GI } & \multicolumn{2}{|c|}{ GII } & \multicolumn{2}{|c|}{ GIII } & \multicolumn{2}{|c|}{ GIV } & \multicolumn{2}{|c|}{ GV } & \multirow[b]{2}{*}{$p$-value } \\
\hline & & $\mathrm{f}$ & $\%$ & $\mathrm{f}$ & $\%$ & $\mathrm{f}$ & $\%$ & $\mathrm{f}$ & $\%$ & $\mathrm{f}$ & $\%$ & \\
\hline & $\mathrm{VL}$ & 2 & 20 & 3 & 30 & 2 & 20 & 1 & 10 & 3 & 3 & \\
\hline & $\mathrm{L}$ & 2 & 20 & 4 & 40 & 2 & 20 & 2 & 20 & 2 & 2 & \\
\hline & BA & 4 & 40 & 2 & 20 & 2 & 20 & 6 & 60 & 5 & 5 & \\
\hline \multirow[t]{7}{*}{ VMI } & A & 2 & 20 & 1 & 10 & 4 & 40 & 1 & 10 & 0 & 0 & 0.468 \\
\hline & $\mathrm{AA}$ & 0 & 0 & 0 & 0 & 0 & 0 & 0 & 0 & 0 & 0 & \\
\hline & $\mathrm{H}$ & 0 & 0 & 0 & 0 & 0 & 0 & 0 & 0 & 0 & 0 & \\
\hline & $\mathrm{VH}$ & 0 & 0 & 0 & 0 & 0 & 0 & 0 & 0 & 0 & 0 & \\
\hline & $\mathrm{VL}$ & 1 & 10 & 0 & 0 & 0 & 0 & 0 & 0 & 1 & 10 & \\
\hline & $\mathrm{L}$ & 0 & 0 & 0 & 0 & 3 & 30 & 1 & 10 & 1 & 10 & \\
\hline & BA & 0 & 0 & 4 & 40 & 4 & 40 & 2 & 20 & 2 & 20 & \\
\hline \multirow[t]{7}{*}{ VP } & A & 6 & 60 & 5 & 50 & 3 & 30 & 4 & 40 & 6 & 60 & 0.246 \\
\hline & $\mathrm{AA}$ & 2 & 20 & 0 & 0 & 0 & 0 & 1 & 10 & 0 & 0 & \\
\hline & $\mathrm{H}$ & 1 & 10 & 1 & 10 & 0 & 0 & 2 & 20 & 0 & 0 & \\
\hline & $\mathrm{VH}$ & 0 & 0 & 0 & 0 & 0 & 0 & 0 & 0 & 0 & 0 & \\
\hline & $\mathrm{VL}$ & 0 & 0 & 0 & 0 & 0 & 0 & 0 & 0 & 1 & 10 & \\
\hline & $\mathrm{L}$ & 1 & 10 & 1 & 10 & 0 & 0 & 0 & 0 & 2 & 20 & \\
\hline & $\mathrm{BA}$ & 1 & 10 & 0 & 0 & 0 & 0 & 1 & 10 & 1 & 10 & \\
\hline \multirow[t]{4}{*}{$\mathrm{MC}$} & A & 5 & 50 & 6 & 60 & 8 & 80 & 4 & 40 & 4 & 40 & 0.733 \\
\hline & AA & 3 & 30 & 2 & 20 & 1 & 10 & 4 & 40 & 2 & 20 & \\
\hline & $\mathrm{H}$ & 0 & 0 & 1 & 10 & 1 & 10 & 1 & 10 & 0 & 0 & \\
\hline & $\mathrm{VH}$ & 0 & 0 & 0 & 0 & 0 & 0 & 0 & 0 & 0 & 0 & \\
\hline
\end{tabular}

Legend: CL: Classification; f: frequency; VMI: visual-motor integration; VP: visual perception; MC: motor coordination. VL: very low; L: low; BA: below average; A: average; AA: above average; H: high; VH: very high.

performance on average or above $(\mathrm{A}, \mathrm{AA}, \mathrm{H})$ and $30 \%$ had below average performance (BA, L); $60 \%$ of the students of GV had performance on average (A) and $40 \%$ had below average performance (BA, L, VL). However, unlike other groups, $30 \%$ of the students of GIII had performance on average or above (A, AA, $\mathrm{H})$ and $70 \%$ had below average performance (BA, L).

Regarding the MC test, $80 \%$ of the students of GI had performance on average or above (A, AA) and only $20 \%$ had below average performance (BA, L); $90 \%$ of 
the students of GII had performance on average or above (A, AA, H) and only $10 \%$ had below average performance (L); all of the students of GIII (100\%) had performance on average or above (A, AA, H); $90 \%$ of the students of GIV had performance on average or above $(\mathrm{A}, \mathrm{AA}, \mathrm{H})$ and $10 \%$ had below average performance (BA); $60 \%$ of the students of GV had performance on average or above (A, AA) and $40 \%$ had below average performance (BA, L, VL).

Table 6 shows the results, analyzed by the Likelihood Ratio Test, of the classification of Dysgraphia Scale, according with the frequency and percentage for quality of handwriting of GI, GII, GIII, GIV and GV.

In Table 6, the results showed that there was significant difference between the classification of Dysgraphia and Non-dysgraphia between the groups. According to this table, $80 \%$ of the students of GI were considerate with Dysgraphia, $10 \%$ of GIII and $60 \%$ of GV. Most of the students from GII, GIII and GIV did not meet sufficient criteria to be considered with Dysgraphia.

A correlation analysis was carried out on the measures of VMI, VP, MC and dysgraphia classification for the whole population. A Bonferroni correction was applied (significant at $p<0.0008$ ). Results are reported in Table 7 showed that only group GV there was two positives correlations with moderate force (Zou, Tunacall, \& Silverman, 2003) between VMI and MC (suggesting that as the students improves MC performance, it impacts the performance of VMI), and between VP and the classification of dysgraphia, suggesting that as the VP skills plays an important role in the classification of dysgraphia for this group.

\section{Discussion}

National literature (Fusco, Cardoso, \& Capellini, 2011; Germano et al., 2013; Germano, Giaconi, \& Capellini, 2016) and international (Leung, Lam, Lam, Pao, \& Li-Tsang, 2014; Overvelde \& Hulstijin, 2011) indicates that elementary school students spend most of their time in school activities as reading and writing, that request visual perception, motor coordination and visomotor integration.

In this study, there was a certain progression in the development of abilities of visual perception, motor coordination and viso-motor integration, when comparing the groups, from the 1 st to 5 th (GI to GV). However, this progression was not so linear. The results showed as in viso-perception ( GI $<$ GII $<$ GIII $<$ GV $<$ GIV), motor coordination (GI $<$ GII $<$ GV $<$ GIII $<$ GIV) and viso-motor integration (GI $<$ GII $<$ GV $<$ GIII $<$ GIV).

Beery and Beery (2010) referred that at the age of 6 years old children acquire important milestone in viso-perception (i.e. viso-perception regarding print

Table 6. Distribution of frequency and percentage of the classification of Dysgraphia Scale for GI, GII, GIII, GIV and GV.

\begin{tabular}{ccccccccccccc}
\hline & \multicolumn{2}{c}{ GI } & \multicolumn{2}{c}{ GII } & \multicolumn{2}{c}{ GIII } & \multicolumn{2}{c}{ GIV } & \multicolumn{2}{c}{ GV } & \\
\hline Classification & $\mathrm{f}$ & $\%$ & $\mathrm{f}$ & $\%$ & $\mathrm{f}$ & $\%$ & $\mathrm{f}$ & $\%$ & $\mathrm{f}$ & $\%$ & $p$-value \\
Dysgraphia & 8 & 80 & 0 & 0 & 1 & 10 & 2 & 20 & 6 & 60 & $<0.001^{*}$ \\
Non-dysgraphia & 2 & 20 & 10 & 100 & 9 & 90 & 8 & 80 & 4 & 40 & \\
\hline
\end{tabular}


Table 7. Correlation between VMI, VP MC and dysgraphia Scale classification of Dysgraphia Scale for GI, GII, GIII, GIV and GV.

\begin{tabular}{|c|c|c|c|c|c|}
\hline & Variable & Statistic & VMI & VP & $\mathrm{MC}$ \\
\hline \multirow[t]{6}{*}{ GI } & VP & Correlation coefficient $(\mathrm{r})$ & 0.314 & & \\
\hline & & $p$-value & 0.377 & & \\
\hline & MC & Correlation coefficient $(\mathrm{r})$ & 0.109 & -0.341 & \\
\hline & & $p$-value & 0.764 & 0.335 & \\
\hline & CL. & Correlation coefficient $(\mathrm{r})$ & -0.544 & -0.197 & -0.094 \\
\hline & & $p$-value & 0.104 & 0.586 & 0.796 \\
\hline \multirow[t]{6}{*}{ GII } & VP & Correlation coefficient $(\mathrm{r})$ & -0.474 & & \\
\hline & & $p$-value & 0.166 & & \\
\hline & MC & Correlation coefficient $(\mathrm{r})$ & 0.022 & 0.136 & \\
\hline & & $p$-value & 0.953 & 0.707 & \\
\hline & CL. & Correlation coefficient $(r)$ & - & - & - \\
\hline & & $p$-value & - & - & - \\
\hline \multirow[t]{6}{*}{ GIII } & VP & Correlation coefficient $(\mathrm{r})$ & -0.234 & & \\
\hline & & $p$-value & 0.515 & & \\
\hline & MC & Correlation coefficient $(\mathrm{r})$ & 0.297 & -0.064 & \\
\hline & & $p$-value & 0.404 & 0.86 & \\
\hline & CL. & Correlation coefficient $(r)$ & 0.242 & 0 & 0.166 \\
\hline & & $p$-value & 0.501 & $>0.999$ & 0.647 \\
\hline \multirow[t]{6}{*}{ GIV } & VP & Correlation coefficient $(\mathrm{r})$ & 0.374 & & \\
\hline & & $p$-value & 0.287 & & \\
\hline & MC & Correlation coefficient $(r)$ & 0.088 & 0.047 & \\
\hline & & $p$-value & 0.81 & 0.897 & \\
\hline & CL. & Correlation coefficient $(r)$ & -0.197 & 0 & 0.371 \\
\hline & & $p$-value & 0.586 & $>0.999$ & 0.291 \\
\hline \multirow[t]{6}{*}{ GV } & VP & Correlation coefficient $(\mathrm{r})$ & 0.045 & & \\
\hline & & $p$-value & 0.903 & & \\
\hline & MC & Correlation coefficient $(\mathrm{r})$ & 0.748 & 0.132 & \\
\hline & & $p$-value & $0.013^{*}$ & 0.717 & \\
\hline & CL. & Correlation coefficient $(\mathrm{r})$ & -0.424 & 0.643 & -0.295 \\
\hline & & $p$-value & 0.222 & $0.045^{*}$ & 0.408 \\
\hline
\end{tabular}

Legend: CL: Classification VMI: visual-motor integration; VP: visual perception; MC: motor coordination.

writing), motor coordination (i.e. use pencil, in a comfortable and efficiently way) and viso-motor integration (i.e. perception of details of form, performs movements in the vertical and horizontal axes that are used in writing).

During writing, orthographic representations are direct into a non-linguistic route, with motor programming and motor-kinematic components. The motor 
programming component comprises several subunits: the graphemic buffer (short-term working memory necessary for attention to and retention of the correct orthographic representation), allographic mechanisms (necessary for case selection and differentiation among similar shaped letters), graphemic motor patterns related to letter production and the spatial representations needed to write on a horizontal line (AdiJapha et al, 2007; Alloway \& Archibald, 2008).

Competent handwriting depends on the maturation and integration of cognitive, visoperceptual, and fine motor skills. Children should become competent handwriters by 6 or 7 years of age, but still, handwriting difficulties are common among children in both regular and special education classrooms (Rosenblum, Weiss, \& Parush, 2004; Tseng \& Chow, 2000).

In this study, $80 \%$ of the students of GI were considerate with Dysgraphia, $10 \%$ of GIII and $60 \%$ of GV. These results of handwriting scale may allow us to observe three different moments, when comparing the grade level, regarding the demand of written activities and the influence of literacy methodology. At 1st grade (GI), we observe a high proportion of students that were characterized with dysgraphia, which diminish at 3rd grade and increased again at 5th grade. The high proportion in 1st grade could be explained by the lack of systematic teaching and practices using fine and/or motor coordination, viso-perception and viso-motor integration activities in kindergarten. Despite the fact of these results from the Dysgraphia Scale seemed to be towards dysfunction, it's important to highlight that there is no scale or test in Brazil for these parameters and this is one of the first's that seeks to establish an estimation of students with dysgraphia, despite the limited number of subjects, and in addition to compare the visual performance with the motor and not the percepto-motor with the writing Concerning Developmental Test of Visual-Motor Integration, for the groups GI and GV, the viso-perception and motor coordination scores had significant contribution in the development of viso-motor integration. Regarding the VMI test, $80 \%$ of the students of GI and $100 \%$ of the students of GV had below average performance. VP test $90 \%$ of the students of GI and $60 \%$ of the students of GV had performance on average and MC test, $80 \%$ of the students of GI had performance on average or above and $60 \%$ of the students of GV had performance on average.

However, unlike other groups, GIII group had scored had below average performance in motor coordination (100\%). This score might had an impact not only in the in the development of viso-motor integration (60\% below average), but also in viso-perception ( $70 \%$ below average).

This finding suggests that at first grade, the students were classified with dysgraphia because of a deficit in the VMI skills. At this level, students are beginning to be exposed to print and activities that demands writing knowledge. Movements needed to handwrite a letter interact with the visual recognition of that same letter. Mental representations of letters may therefore not be strictly visual, but instead based on a complex neural network that includes a sensory-motor component acquired while learning to read and write concomitantly. 
In other words, it is multisensory experience, as they can be seen, handwritten, read, heard, or typed, so learning reinforces both their motor and visual representations. Taken together, these studies highlight the role of action over perception, and indicate that there are strong connections between the visual-perceptual and motor components of reading and writing (Bara, Morin, Alamargot, \& Bosse, 2016).

At 3rd grade (GIII), the students are more exposed to text, which demands even more handwriting activities. At 5th grade (GV), the role of viso-motor skills should have been acquired and automatized. This imply that the student shift from the demand of viso-perception or motor coordination according with class activities. However, there are none national studies about this. Another implication for the student from 5th grade is the possible effect in their academic activities. According with Wallen et al. (2013), students with handwriting difficulties or developing handwriters have reduced capacity for idea generation, planning and revision when required to focus on the mechanics of handwriting in addition to the demands of composing written work.

Ratzon et al. (2009) referred that visual-motor integration is defined as integration between visual, perceptual, and motor skills. Visual-motor integration is a part of visual perception skills with emphasize on its motor component. Good visual-motor integration function is depending on maturation, and integration of cognitive, visual, perceptual, and motor skills.

The author suggests that visual-motor integration is one of the main activities to prepare children for handwriting. Handwriting, and copying, the same as visual- motor integration, require visual identification of form and position in space, giving meaning to letters' form, and performing motor manipulation for producing letters. Studies focusing on handwriting prove to show significant associations between visual-motor integration and handwriting quality, fluency and legibility.

\section{Conclusion}

The results of this study showed that it was possible to characterize and compare the perceptual performance and viso-motor and writing school from the 1st to 5th grade of elementary school. Regarding the perceptual and viso-motor test, students from all groups had difficulties in viso-motor integration, visual perception and motor coordination. The viso-motor integration was the ability that all groups had lower score and motor coordination was the ability that all groups had better performance. It was possible to observe that there was not a clear progression in the acquisition of this skill, which might suggest a lack of teaching of strategies in classroom.

In addition, the results showed that at the beginning of school year (the 1st grade), most of the students were classified with dysgraphia, which emphasizes that the students start the alphabetization process without some essential skills, such as viso-perception and motor coordination. This finding brings an important impact to educational policy. 
This dysgraphia percentage diminished among the grades, but kept substantial in the 5th grade, indicating that the handwriting is still affected by the viso-motor integration, visual perception and motor coordination skills.

\section{Acknowledgements}

To Brazilian National Council for Scientific and Technological Development (CNPq) for supporting this research (Universal Notice MCT/CNPq number 455208/20140).

\section{References}

Adi-Japha, E., Landau, Y. E., Frenkel, L., Teicher, M., Gross-Tsur, V., \& Shalev, R. S. (2007). ADHD and Dysgraphia: Underlying Mechanisms. Cortex, 43, 700-709.

Alloway, T. P., \& Archibald, L. (2008). Working Memory and Learning in Children with Developmental Coordination Disorder and Specific Language Impairment. Journal of Learning Disabilities, 41, 251-262. https://doi.org/10.1177/0022219408315815

Alston, J., \& Taylor, J. (1987). Handwriting: Theory, Research and Practice. New York: Nichols Publishing Company.

American Psychiatric Association (2013). Diagnostic and Statistical Manual of Mental Disorders (DSM-5). American Psychiatric Pub.

Andrade, S. M., Dias, M. M. C. B. S., Oliveira, E. A., Locks Neto, F., Nogueira, R. M. T. B. L., \& Santos, N. A. (2012). Construction and Psychometric Evidences of a Visual Perception Scale. Psychology: Research and Review, 25, 21-29.

Bara, F., Morin, M. F., Alamargot, D., \& Bosse, M. L. (2016). Learning Different Allographs through Handwriting: The Impact on Letter Knowledge and Reading Acquisition. Learning and Individual Differences, 45, 88-94.

Beery, K. E., \& Beery, N. A. (2010). The Beery-Buktenica Developmental Test of VisualMotor Integration: Administration, Scoring, and Teaching Manual (6th Ed.). Minneapolis, MN: NCS Pearson.

Fusco, N., Cardoso, M. H., \& Capellini, S. A. (2011). Intervention with the Viso-Motor Perception in Students with Learning Problems. In A. A. Ribeiro (Ed.), Themes in Cognition, Language and Learning (pp. 179-188). Ubá MG: Suprema Editora Ltda.

Foundation of Economy and Statistics. Índice de Desenvolvimento Socioeconômico (Idese) [Internet]. Porto Alegre: FEE; 2003.] [citado 2010 Ago 10]. Disponível em: http://revistas.fee.tche.br/index.php/ensaios/article/viewFile/2983/3732

Germano, G. D., Giaconi, C., \& Capellini, S. A. (2016). Characterization of Brazilians Students with Dyslexia in Handwriting Proficiency Screening Questionnaire and Handwriting Scale. Psychology Research, 6, 590-597.

Germano, G. D., Pinheiro, F. H., Okuda, P. M. M., \& Capellini, S. A. (2013). Visual-Motor Perception in Students with Attention Deficit with Hyperactivity Disorder. CoDAS, 25, 337-341. https://doi.org/10.1590/S2317-17822013000400007

Johnson, D. J., \& Carlisle, J. F. (1996). A Study of Handwriting in Written Stories of Normal and Learning Disabled Children. Reading and Writing, 8, 45-59.

Lahav, O., Apter, A., \& Ratzon, N. Z. (2013). Psychological Adjustment and Levels of Self-Esteem in Children with Visual-Motor Integration Difficulties Influences the Results of a Randomized Intervention Trial. Research in Developmental Disabilities, 34, 56-64. https://doi.org/10.1016/j.ridd.2012.07.024

Leung, M. M., Lam, C. S., Lam, S. S., Pao, N. W., \& Li-Tsang, C. W. (2014). Visual Profile of Children with Handwriting Difficulties in Hong Kong Chinese. Research in Deve- 
lopmental Disabilities, 35, 144-152. https://doi.org/10.1016/j.ridd.2013.10.013

Lorenzini, M. V. (2003). A Scale for Detecting the Dysgraphia Based on the Ajuriaguerra Scale. Unpublished Master's Dissertation, São Carlos: Universidade Federal de São Carlos.

Martins, M. R. I., Bastos, J. A., Cecato, A. T., Araujo, M. D. L. S., Magro, R. R., \& Alaminos, V. (2013). Screening for Motor Dysgraphia in Public Schools. Jornal de Pediatria (Brazilian Society of Pediatrics), 89, 70-74.

https://doi.org/10.1016/j.jped.2013.02.011

Okuda, P. M. M., Pinheiro, F. H., Germano, G. D., Padula, N. A. M. R., Lourencetti, M. D., Santos, L. C. A., \& Capellini, S. A. (2011) Fine Motor, Sensory and Perceptive Function of Students with Attention Deficit Disorder with Hyperactivity. Jornal Sociedade Brasileira de Fonoaudiologia (Brazilian Society of Speech-Language Pathology and Audiology), 23, 351-357. https://doi.org/10.1590/S2179-64912011000400010

Overvelde, A., \& Hulstijn, W. (2011). Handwriting Development in Grade 2 and Grade 3 Primary School Children with Normal, at Risk, or Dysgraphic Characteristics. Research in Developmental Disabilities, 32, 540-548. https://doi.org/10.1016/j.ridd.2010.12.027

Pereira, D. M., Araújo, R. D. C. T., \& Braccialli, L. M. P. (2011). Relationship Analysis between Visual-Motor Integration Ability and Academic Performance. Journal of Human Growth and Development, 21, 808-817. https://doi.org/10.7322/jhgd.20033

Pieters, S., Desoete, A., Roeyers, H., Vanderswalmen, R., \& Van Waelvelde, H. (2012). Behind Mathematical Learning Disabilities: What about Visual Perception and Motor Skills? Learning and Individual Differences, 22, 498-504.

https://doi.org/10.1016/j.lindif.2012.03.014

Ratzon, N. Z., Lahav, O., Cohen-Hamsi, S., Metzger, Y., Efraim, D., \& Bart, O. (2009). Comparing Different Short-Term Service Delivery Methods of Visual-Motor Treatment for First Grade Students in Mainstream Schools. Research in Developmental Disabilities, 30, 1168-1176.

Rosenblum, S., Weiss, P. L., \& Parush, S. (2004). Handwriting Evaluation for Developmental Dysgraphia: Process versus Product. Reading and Writing, 17, 433-458.

https://doi.org/10.1023/B:READ.0000044596.91833.55

Vinter, A., \& Chartrel, E. (2010). Effects of Different Types of Learning on Handwriting Movements in Young Children. Learning and Instruction, 20, 476-486. https://doi.org/10.1016/j.learninstruc.2009.07.001

Sovik, N., \& Arntzen, O. (1991). A Developmental Study of the Relation between the Movement Patterns in Letter Combinations (Words) and Writing. In J. Wann, A. M. Wing, \& N. Sovik (Eds.), Development of Graphic Skills: Research Perspective and Educational Implications (pp. 77-89). New York: Academic Press.

Tseng, M. H., \& Chow, S. M. K. (2000). Perceptual-Motor Function of School-Age Children with Slow Handwriting Speed. American Journal of Occupational Therapy, 54, 83 88. https://doi.org/10.5014/ajot.54.1.83

Van Galen, G. P. (1993). Handwriting: A Developmental Perspective. In A. F. Kalverboer, B. Hopkins, \& R. Geuze (Eds.), Motor Development in Early and Later Childhood: Longitudinal Approaches (pp. 217-228). New York: Cambridge University Press. https://doi.org/10.1017/CBO9780511663284.016

Wallen, M., Duff, S., Goyen, T.-A., \& Froude, E. (2013), Respecting the Evidence: Responsible Assessment and Effective Intervention for Children with Handwriting Difficulties. Australian Occupational Therapy Journal, 60, 366-369.

Zou, K. H., Tuncali, K., \& Silverman, S. G. (2003). Correlation and Simple Linear Regression. Radiology, 227, 617-628. https://doi.org/10.1148/radiol.2273011499 
Submit or recommend next manuscript to SCIRP and we will provide best service for you:

Accepting pre-submission inquiries through Email, Facebook, LinkedIn, Twitter, etc. A wide selection of journals (inclusive of 9 subjects, more than 200 journals)

Providing 24-hour high-quality service

User-friendly online submission system

Fair and swift peer-review system

Efficient typesetting and proofreading procedure

Display of the result of downloads and visits, as well as the number of cited articles Maximum dissemination of your research work

Submit your manuscript at: http://papersubmission.scirp.org/

Or contact psych@scirp.org 